\title{
EXPERIMENTAL EVALUATION OF THE URETHRAL RESPONSE TO SECTION OF THE SPINAL CORD OR CAUDA EQUINA AND TO THE ELECTROSTIMULATION OF THE BLADDER IN NON-HUMAN PRIMATES
}

\author{
By G. F. Murnaghan, M.D., Ch.M., F.R.C.S.(Ed.), F.R.C.S., F.R.A.C.S., \\ S. P. Gowland, F.R.A.C.S., M. A. Rose, B.V.Sc., R. J. Millard, F.R.C.S., \\ F.R.A.C.S., and W. A. STENING, F.R.C.S.(Ed.) \\ Department of Surgery, University of New South Wales, The Prince Henry Hospital, Little \\ Bay, Sydney, New South Wales, Australia
}

Abstract. Studies of urethral function in 32 female monkeys indicate a dual innervation of the mid-urethra from sympathetic and somatic supply. The resting urethral pressure profiles were preserved after low level section of the spinal cord or division of the cauda equina. They had lowered amplitude after overstretch or electrostimulation of the autonomous bladder.

Key words: Neurogenic bladder; Urethra; Urodynamics; Physiopathology; Monkeys.

\section{Introduction}

PRECISE evaluation of abnormal function of the urethra in the paraplegic patient is confounded by the unstable neurological and urological states which may accompany mixed neural lesions and generally defy clinical analysis. Experimental observations of normal and abnormal micturition may involve procedures which are inapplicable to clinical practice and may be irrelevant because of inter-species differences. Recent studies in the monkey (Macaca nemestrina) have indicated that this animal has a sacral spinal centre for micturition whereby primary patterns of neurogenic disorder after supra-sacral spinal cord section and after cauda equina section closely resemble the clinical presentations in man and justify the use of this animal model for evaluation of the neurological mechanism of micturition (Murnaghan, 1976).

Evidence has been obtained that the monkey may have a dual innervation of the urethra with indications that the amplitude of the mid-urethral pressure profile has a variable dependency upon central connections in the nervous system (Murnaghan et al., 1978). More precise evaluation of the neural control of the urethra in the monkey before and after section of the spinal cord or cauda equina has now been undertaken and the results of these studies are reported with some reference to urethral function during induced electro-stimulation of the bladder.

\section{Material and Methods}

Observations have been made upon a group of 32 female monkeys (Macaca nemestrina). Urological studies comprised recording of urethral pressure profiles and cystometry.

This project has been supported by a Grant-in-Aid from The Australian Kidney Foundation. 
Urethral pressure profiles were recorded during constant infusion at $\mathrm{I} \cdot 5 \mathrm{ml}$ per minute through a urethral catheter $(5 \mathrm{~F})$ with a single lateral outlet and during withdrawal by a motorised trombone as described by Harrison and Constable (1970) and as used in clinical practice.

In the initial studies cystometry was carried out by suprapubic bladder puncture with infusion at $5 \mathrm{ml}$ per minute. The later cystometric studies used separate urethral catheters $(3 \mathrm{~F})$ for filling and recording; this method was found to be less traumatic to the bladder detrusor with repetitive study and was compatible with chronic implantation of pacemaker devices.

After controlled studies the animals were variously subjected to: (I) acute stimulation of the pre-sacral or pudendal nerves; (2) acute pharmacological simulation of stimulation or blockade of autonomic or somatic innervation; (3) section of the spinal cord; (4) division of the cauda equina with or without overstretch of the bladder; or (5) induced electrostimulation of the bladder before and after surgical section of the cauda equina.

In eight animals urinary diversion by uretero-colic anastomosis preceded the induction of a central neurosurgical lesion in order to prevent uncontrolled stretching of the bladder wall during any phase of spinal shock and between subsequent investigations.

Direct electrostimulation of either the pre-sacral nerve in the retro-peritoneum or the pudendal nerve exposed in the ischiorectal fossa was administered through bi-polar platinum hook electrodes using a stimulus between $\mathrm{I} \cdot 0 \mathrm{v}$ to $6.0 \mathrm{v}$; a $3.0 \mathrm{v}$ stimulus was generally found to be the most effective when used with a time constant of I m sec at $1000 \mathrm{~Hz}$.

Induced electrostimulation of the bladder was obtained with the Mentor ${ }^{1}$ bladder stimulator (Merrill \& Conway, 1974) with attempted positioning of the electrodes of the paediatric device around the neuro-vascular pedicle of the bladder and with imbrication of the detrusor muscles over the electrodes as detailed by Merrill (1974). Difficulties were encountered in housing the bladder stimulator in a subcutaneous pouch of the lower abdomen but long-term accommodation of the device was obtained in a Dacron mesh hammock suspended from the lower abdominal wall in the extraperitoneal space.

Profile studies and cystometry required light anaesthesia which was obtained by the intra-muscular administration of ketamine ( $10 \mathrm{mg} / \mathrm{kg}$ body weight). Operative procedures were undertaken during general anaesthesia which was induced by intravenous administration of ketamine and maintained by closed circuit, endotracheal, inhalation administration of nitrous oxide, oxygen and halothane.

In the absence of standardised drug dosage schedules for these animals the dosage of those drugs with anticipated autonomic responses was adjusted so that a clear response was reflected in monitored blood pressure levels. EMG recordings were used to control adequate administration of muscle relaxants. More accurate assessment of drug dosage was accomplished by special study of two animals in which chronic indwelling catheters were maintained in the aorta and vena cava for periods of up to seven weeks. Such catheters allowed for repeated infusion of drugs rather than bolus injection so that the long term residual effects of drugs were minimised and the possibility of adaptive or reinforcing responses to repeated administration was reduced. Individual drug administrations were made at intervals not less than 48 hours and though each drug was administered to each animal on two occasions, the sequence and choice of drugs were randomised.

${ }_{1}$ Mentor Corporation, 3104 West Lake Street, Minneapolis, Minnesota, 554I6, U.S.A. 
After drug administration the urethral pressure profiles were always compared with matched controlled studies which had been recorded at comparable stages of bladder filling.

\section{Control studies}

\section{Results}

The control urethral pressure profiles obtained from the female monkey with the bladder empty and under ketamine anaesthesia were found to have a midurethral high peak of about $20 \mathrm{mmHg}$ but the bladder neck and distal urethral regions of the profile were flat. Though the profile varied from animal to animal it was found to be reproducible in the same animal under repeated light anaesthesia and under halothane anaesthesia (Fig. I). Filling of the control bladder produced slight augmentation of the urethral profile until voiding capacity was approached; the profile then tended to reduce its amplitude slightly as an immediate prelude to voiding which abolished the profile.

The normal bladder responded to constant infusion via the suprapubic or urethral catheters with a gradual rise in intravesical pressure to about Io $\mathrm{mmHg}$ with intrinsic activity after $30 \mathrm{ml}$ of filling to produce voiding with a peak pressure as high as 30 or $40 \mathrm{mmHg}$ (Fig. 2).

Studies indicated that normal urethral pressure profiles and cystometric patterns were preserved up to 90 days after urinary diversion by uretero-colic anastomosis.

\section{Intact urethral innervation}

Observations in a group of seven monkeys showed that augmentation of the mid-urethral pressure profile followed stimulation of the pre-sacral nerve, or the

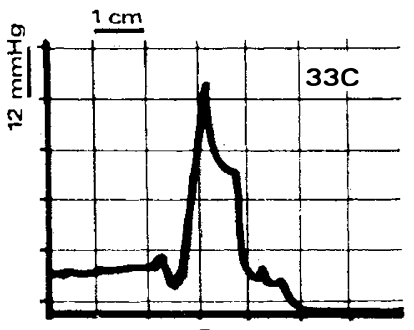

A

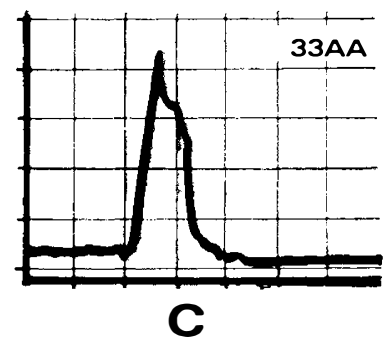

FIG. I

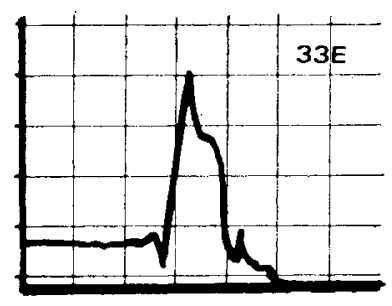

B

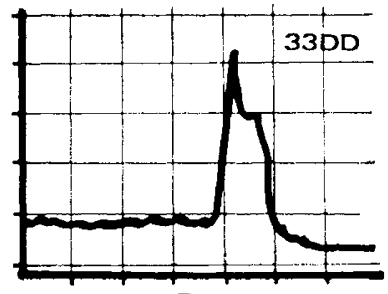

D

Diagrams of urethral pressure profiles of female monkey under $(a)$ light ketamine, $(b)$ deep ketamine anaesthesia on the same day and $(c)$ under ketamine and $(d)$ halothane anaesthesia one week later. 


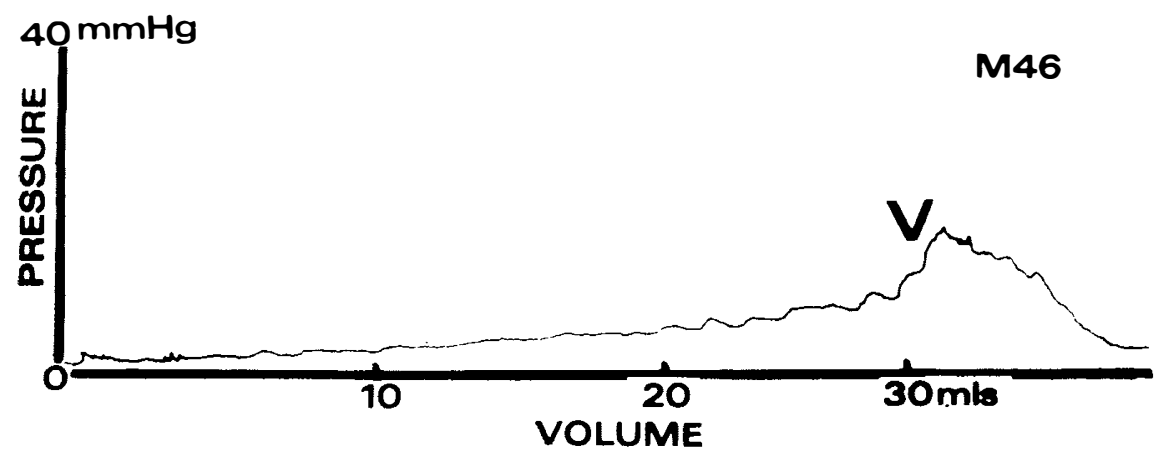

FIG. 2

Normal cystometrogram in female monkey. (V: voiding.)

administration of noradrenaline ( $20 \mu \mathrm{g} / \mathrm{kg}$ body weight). In another group of five monkeys augmentation of the mid-peak of the profile followed stimulation of the pudendal nerve (Fig. 3).

Repetitive administration of drugs to other monkeys in groups never smaller than two animals showed that the mid-urethral profile was also augmented by adrenaline ( $20 \mu \mathrm{g} / \mathrm{kg}$ body weight) (Fig. 3) but was markedly reduced in amplitude by the administration of phentolamine mesylate $(2 \mathrm{mg} / \mathrm{kg}$ body weight), propranolol ( $\mathrm{I} \mathrm{mg} / \mathrm{kg}$ body weight), and to a lesser degree by suxamethonium chloride (3-5 $\mathrm{mg} / \mathrm{kg}$ body weight), carbachol (I $\mu \mathrm{g} / \mathrm{kg}$ body weight) or atropine ( $0 . \mathrm{I} \mathrm{mg} / \mathrm{kg}$ body weight) (Fig. 4).

Augmentation of the profile by presacral nerve stimulation or by noradrenaline could be abolished or diminished by the intravenous administration of phentolamine (Fig. 5) to produce blockade of the alpha-adrenergic receptors. When the mid-urethral peak of the resting profile had already been lowered by such a blockade with phentolamine it was still possible to obtain augmentation of the profile by electrostimulation of the pudendal nerve. In one experiment this restorative and supportive effect on the profile during continued blockade of the alpha receptors was abolished by the intravenous administration of curare $(2 \mathrm{mg} / \mathrm{kg}$ body weight). In five animals augmentation of the mid-peak of the profile by pudendal nerve stimulation was blocked by the previous intravenous administration of suxamethonium chloride (Scoline) (Fig. 5).

\section{Urethral response after spinal cord section}

In two animals sequential studies were undertaken after complete transverse section of the spinal cord above the sacral centre for micturition and at variable intervals of time remote from urinary diversion. The profiles showed some loss of amplitude in the immediate post-operative phase and then developed some broadening of the base of the profile in the distal urethra on the first post-operative day. By the 8th day after spinal cord section the profiles had returned to the preoperative form (Fig. 6). Cystometry at the same intervals showed a rather tonic filling curve but with a voiding response to filling even at two hours after neurosurgery and without any evidence of hypotonic bladder response to acute cord section. On the first post-operative day co-ordinated reflex bladder contractility was defined and this became well established by the 8th post-operative day in a pattern thought to be typical of reflex neurogenic bladder disturbance with some 

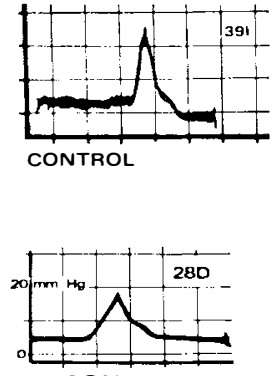

CONTROL

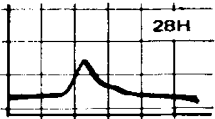
CONTROL

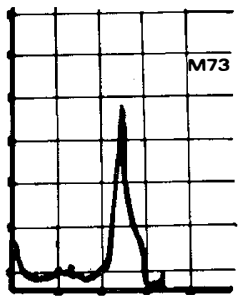

CONTROL
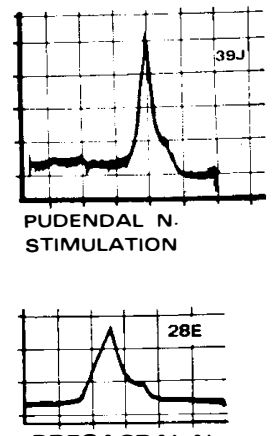

PRESACRAL $N$. STIMULATION $6 \mathrm{~V}$

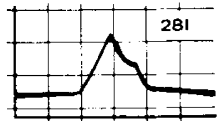

NORADRENALINE

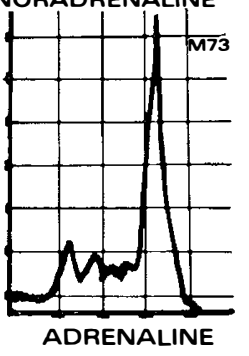

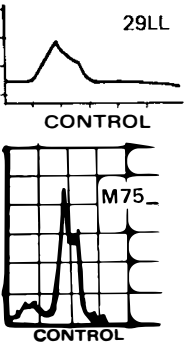
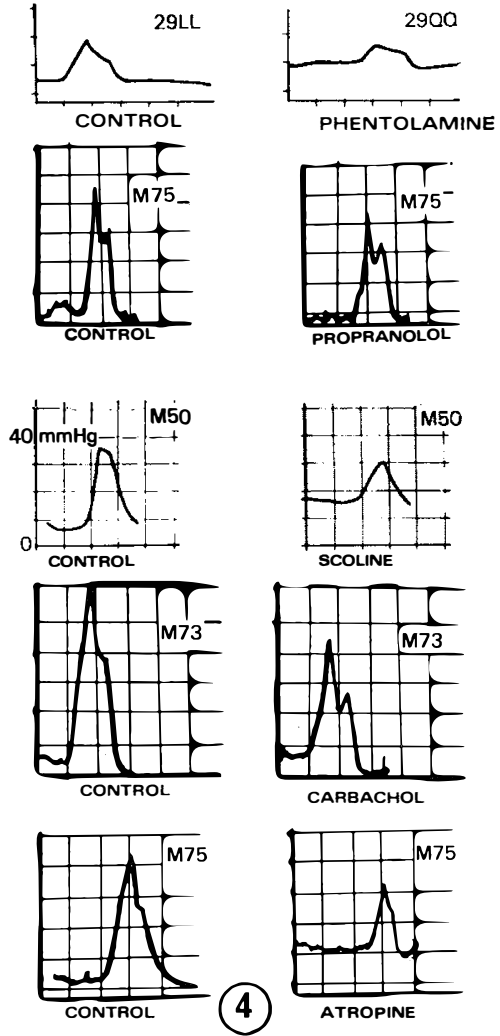

FIG. 3

Diagrams of urethral pressure profiles showing augmentation by stimulation of the pudendal or pre-sacral nerves and after the administration of noradrenaline or adrenaline.

FIG. 4

Diagrams of urethral pressure profiles showing the lowered amplitudes after phentolamine, propranolol, Scoline, carbachol or atropine.

urinary incontinence but with co-ordinated responses productive of voiding with bladder emptying (Fig. 6).

\section{Urethral response after cauda equina section}

The effects of complete section of the cauda equina through lumbar laminectomy were assessed in I3 animals, five of which had previously undergone urinary diversion and three of which were implanted with the Mentor pacemaker device and without diversion.

In the early stages after cauda equina section there was some possible widening of the base of the urethra profile but it was again remarkable to note that the profile returned to the pre-operative postdiversion state by the 8th day after cauda equina section (Fig. 7). Filling of the bladder after cauda equina section produced augmentation of the urethral profile during the early phase of bladder adaptation but with further filling to the stage of dribbling overflow incontinence, the profile was reduced in length and amplitude as compared with the control profile taken with the bladder empty. 

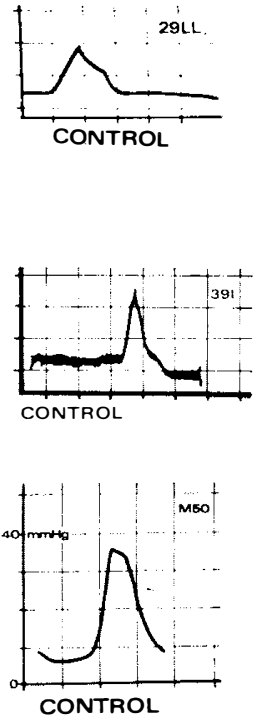
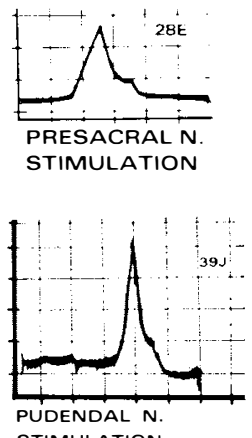

STIMULATION

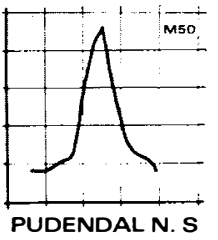

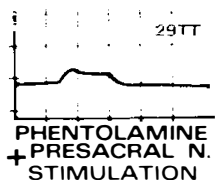

STIMULATION

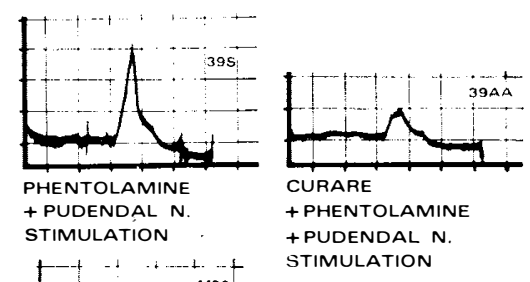

TIMULATION

FIG. 5

Diagrams of urethral pressure profiles showing the effects of the administration of phentolamine, curare or Scoline upon the responses to stimulation of either the pre-sacral or pudendal nerves.
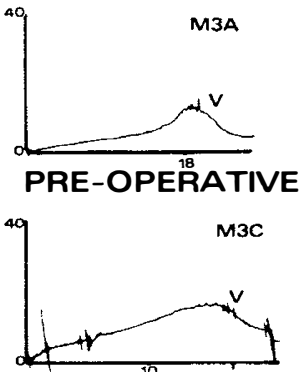

2HOURS POST-OPERATIVE

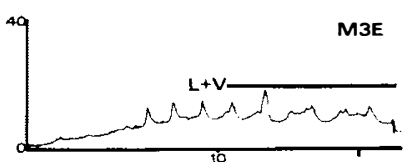

1DAY POST-OPERATIVE

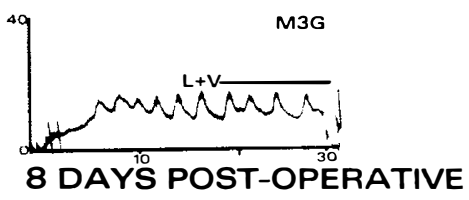

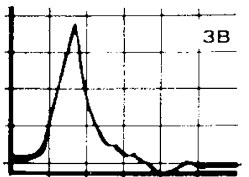
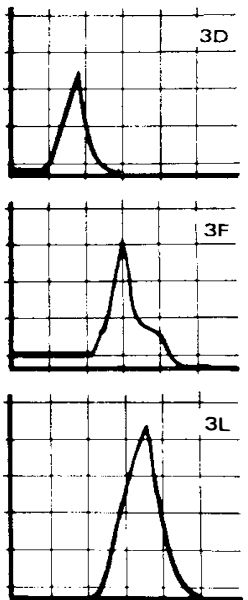

FIG. 6

Cystometrograms and diagrams of urethral pressure profiles before and after section of the spinal cord and remote from urinary diversion. 

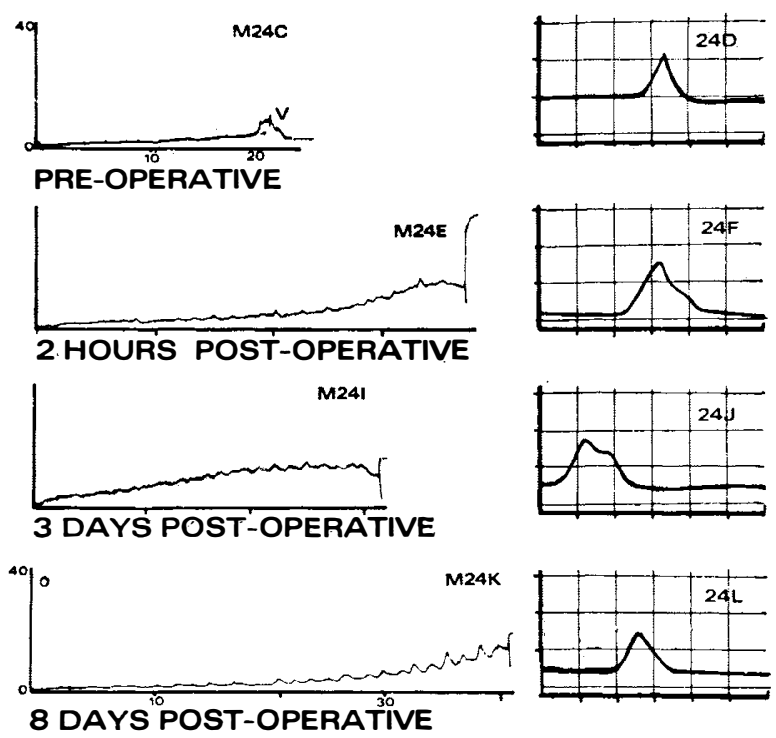

FIG. 7

Cystometrograms and diagrams of urethral pressure profiles before and after section of the cauda equina and remote from urinary diversion.

An autonomous pattern of fibrillary tonic bladder response to filling was defined on cystometry some 2 hours after section of the cauda equina and was associated with variable dribbling but without co-ordinated detrusor activity and without the induction of micturition. Significant intrinsic bladder tonus was still observed at the 8th post-operative day in association with good capacity of the bladder which had been protected from endogenous overstretch by previous urinary diversion (Fig. 7).

When the cauda equina section was carried out without previous urinary diversion an autonomous pattern of bladder disturbance developed at higher pressure but with decline in the amplitude of urethral pressure profile by the 8 th post-operative day (Fig. 8).

\section{Urethral response after overstretch of the autonomous bladder}

In three animals already subjected to urinary diversion and surgical section of the cauda equina, overstretch of the autonomous bladder was attempted by the infusion of $120 \mathrm{ml}$ of sterile normal saline through a urethral catheter or by suprapubic puncture for a 3-hour period on three occasions during the first 8 days after neurosurgery. In three further animals without previous diversion overstretch of the bladder was attempted after cauda equina section by the administration of parenteral fluid overload with induced diuresis and without instrumentation of the lower urinary tract. Diuresis was induced by the intravenous administration of 100 $\mathrm{ml}$ per hour of 5 per cent dextrose in Hartmann's solution during 3 hours on each of the $2 \mathrm{nd}, 4^{\text {th }}$, 7 th and 8 th days after cauda equina section together with the intravenous administration of $10 \mathrm{mg}$ of frusemide at the end of the first hour; frusemide $(20 \mathrm{mg}$ ) was administered orally on each of the other post-operative days. 

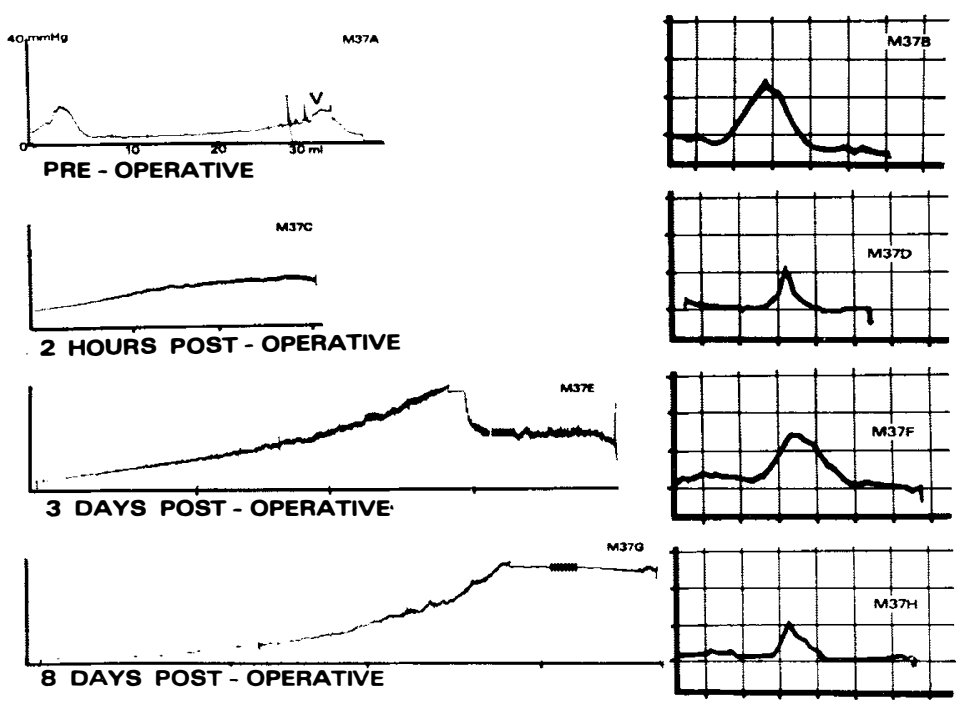

FIG. 8

Cystometrograms and diagrams of urethral pressure profiles before and after section of the cauda equina without previous urinary diversion.

Changes in the cystometric pattern of the autonomous bladder were variable after overstretch and regardless of the method used. The overstretch was generally followed by significant increase in bladder capacity and the development of raised autonomous intrinsic bladder tonus sometimes in association with the development of high amplitude regular detrusor contractions. Hypotonia or large capacity atonic bladder derangement were never induced.

Deliberate overstretch of the bladder after cauda equina section showed a marked association with a fall in the amplitude in the mid-peak of the resting urethral pressure profile but this could be restored to control levels by the intravenous administration of noradrenaline (Fig. 9).

\section{Urethral response to electrostimulation of the bladder}

The Mentor bladder pacemaker device was implanted into each of five monkeys. One of these animals developed infection in a retropubic haematoma and was sacrificed on the Ioth post-operative day. A second animal developed urethral stenosis which could not be attributed to the pacemaker implantation but which prevented further study. Control urethral profiles for the evaluation of electrostimulation of the bladder were taken with the bladder full.

In two animals, urethral pressure profiles and cystometric patterns, though not simultaneous, were recorded during induced electrostimulation of the bladder some 6 or 7 weeks after implantation of the Mentor device but before section of the cauda equina. During stimulation there was augmentation of the urethral pressure profile and this augmentation was blocked by previous administration of phentolamine (Fig. IO). In one of these two animals electrostimulation which was responsible for augmentation of the profile was not accompanied by any significant bladder response when applied during cystometry; in the second animal stimulation $18 / 4-\mathrm{C}$ 

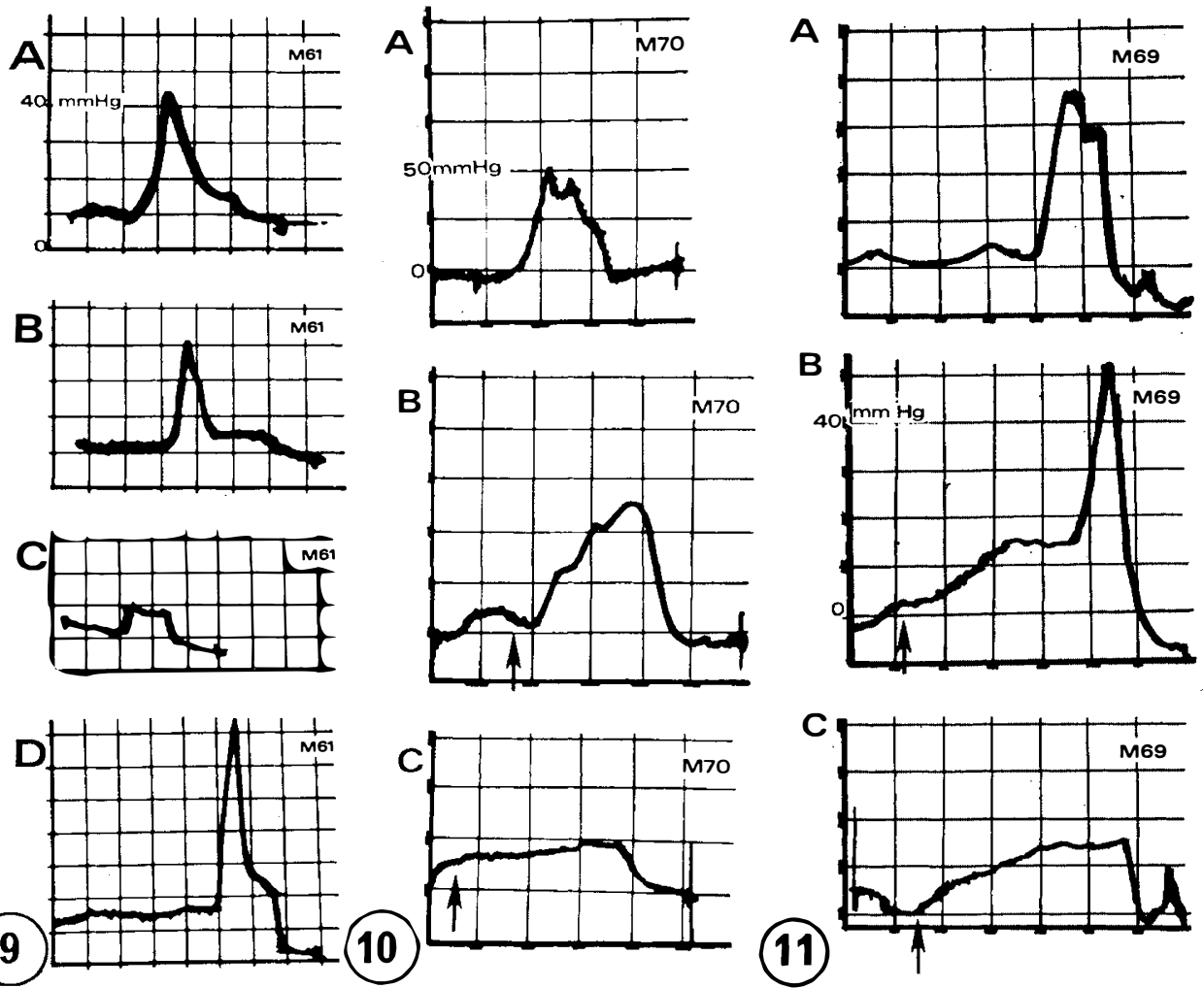

FIG. 9

Diagrams of urethral pressure profiles showing decline from (a) the control profile, to $(b)$ a low amplitude after cauda equina section without urinary diversion and further lowering to (c) as a result of overstretch of the bladder and with restoration of the profile to $(d)$ after the administration of noradrenaline.

FIG. IO

Diagrams of urethral pressure profiles before cauda equina section, 7 weeks after implantation of the bladder pacemaker: $(a)$ before stimulation of the bladder; $(b)$ during stimulation of the bladder; and $(c)$ during stimulation after the administration of phentolamine.

FIG. I I

Diagrams of urethral pressure profiles taken $3 \mathrm{I}$ days after section of the cauda equina and overstretch of the bladder: $(a)$ control; $(b)$ with augmentation during bladder stimulation; and $(c)$ without augmentation during bladder stimulation after the administration of phentolamine.

produced electromicturition during cystometry. In these experiments electrostimulation of the bladder was maintained throughout the recording of the urethral pressure profiles.

In an acute study immediately after implantation of the stimulator in one animal, 3I days after surgical section of the cauda equina and following repeated induced overstretch of the autonomous bladder, augmentation of the urethral profile was obtained by electrostimulation of the bladder and this augmentation was prevented by alpha-adrenergic blockade with phentolamine (Fig. I I).

In more chronic preparations in two animals where implantation of the stimulator had preceded surgical section of the cauda equina by 6 or 7 weeks and 
when the stimulus was applied during the first 2 weeks after cauda equina section, then it was noted that electrostimulation of the bladder produced depression rather than augmentation of the profile. Following deliberate overstretch of the bladder in one of these animals, some 3 weeks after section of the cauda equina, it was found that electrostimulation of the bladder was followed by augmentation of the profile and this effect could be blocked by the administration of phentolamine. The second animal was not subjected to bladder overstretch after cauda equina section and showed lowering of the profile amplitude in response to either electrostimulation or the administration of phentolamine. Electrostimulation of the bladder after the administration of phentolamine caused almost complete loss of urethral pressure profile (Fig. I2).

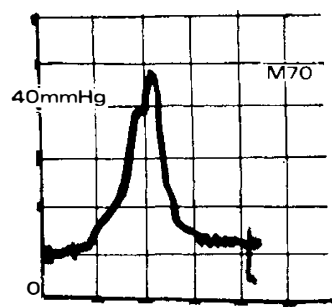

A

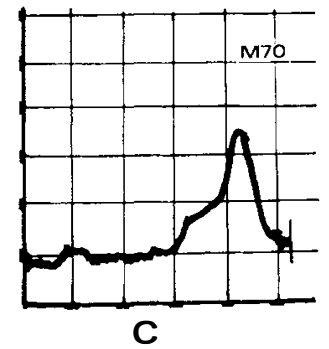

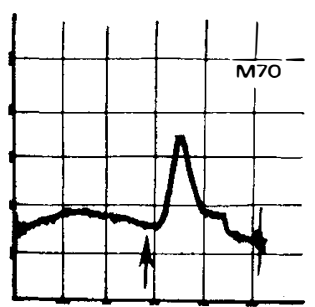

B

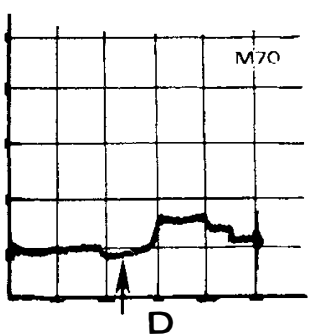

FIG. I2

Diagrams of urethral pressure profiles taken 9 weeks after implantation of a bladder pacemaker and 2 weeks after section of the cauda equina: $(a)$ before electrostimulation of the bladder; (b) during electrostimulation of the bladder; $(c)$ after phentolamine administration; and $(d)$ during electrostimulation after phentolamine.

\section{Discussion}

Though the animals used in this study were of comparable age and weight there was wide variation in amplitude of resting urethral pressure profiles. The profiles of individual animals were reproducible but a 'normal' profile for the female monkey of this species was not defined. A constant pattern of response to various neural agents did emerge to indicate that the animal has a dual innervation of the mid-urethra where the profile is supported by alpha-adrenergic receptors as well as a somatic neural component. The contributions of the beta-adrenergic and parasympathetic components of the autonomic supply were less striking and somewhat irregular but only a few animals were used in their evaluation and further studies are required.

Preservation of the profile after low level cord section or cauda equina section supports the possible dominance of sympathetic innervation in the control of 
urethral tonus in the monkey. Donker et al. (1972) came to the same conclusion in respect of human subjects.

After cauda equina section in the diverted series of experiments the profile heights were not significantly lower than the pre-operative controls and these findings contrast with the clinical observations of Sham Sunder and his associates (I978). Lowering of the profile after experimental section of the cauda equina was associated either with overstretch or with electrostimulation of the autonomous bladder.

Augmentation of the profile followed electrostimulation of the bladder before neurosurgery; blockade of this response by phentolamine would implicate the alpha-adrenergic component of urethral innervation. Reversal of the augmentation response to electrostimulation by section of the cauda equina and persistence of the lowering effect of electrostimulation after phentolamine, might, however, implicate other neural mechanisms. Augmentation of the profile by electrostimulation of the autonomous bladder after overstretch was similar to the response to noradrenaline under the same experimental conditions. After cauda equina section the central sympathetic nervous connections were intact in these animals so that the variations in the inter-relationship between bladder status and the urethral pressure profile could not be attributed to the vesical plexus with any certainty.

\section{RÉSUMÉ}

Des études du fonctionnement urètre chez 32 singes femelles suggèrent que l'innervation du mi-urètre est à la fois sympathique et somatique. Les profiles de la pression basale de l'urètre préservaient suivant la section au bas niveau de la corde spinale au du cauda equina. Ils manifestent une amplitude diminué après la surtension ou la stimulation électrique de la vessie autonome.

\section{ZUSAMMENFASSUNG}

Studien der urethralen Funktion in 32 weiblichen Affen zeigt eine zweifache Inervation der Mitt-urethra von sympathischer und somatischer Nervenversorgung. Die ruhenden Urethradruchprofile wurden durch niedrige, waagerechte Spaltung des Rückenmarks oder der cauda equina erhalten. Sie haben erniedrigte Höhe nach Überspannung oder electrischer Anreizung der un abhängigen Blase.

\section{REFERENCES}

Donker, P. J., Ivanovici, F. \& Noach, E. L. (1972). Analyses of the urethral pressure profile by means of electromyography and the administration of drugs. Brit. F. Urol., 44, I80-I93.

HARRISON, N. W. \& Constable, A. R. (1970). Urethral pressure measurement: a modified technique. Brit. F. Urol., 42, 229.

MerRILL, D. C. (1974). Clinical experience with the Mentor bladder stimulator. II. Meningomyelocele patients. F. Urol., I12, 823-825.

MerRILl, D. C. \& Conway, C. J. (I974). Clinical experience with Mentor bladder stimulator. I. Patients with upper motor neuron lesions. F. Urol., II2, 52-56.

MURNAGHAN, G. F. (1976). Experimental neurogenic bladder disorder in non-human primates. Proc. of the Far East and South Pacific Spinal Cord Conf., Sydney, pp. 197202.

Murnaghan, G. F., Gowland, S., Rose, M., Lalak, A. \& Murphy, D. (1978). Experimental neurogenic disorders of the urinary bladder in non-human primates. Trans. 89th Annual Meeting Amer. Asso. Genito-Urin. Surg., Florida.

Sham Sunder, G., Parsons, K. F. \& Gibbon, N. O. K. (1978). Outflow obstruction in neuropathic bladder dysfunction: the neuropathic urethra. Brit. F. Urol., 50, 190-199. 